\title{
Diabetes, obesity and metabolic syndrome models studied in zebrafish - further relevance for the neuropsychiatric disorders-related manifestations
}

\author{
Iuliana Simona Luca, Irina Dobrin, Alin Ciobîcă \\ Alexandru Ungureanu, Daniel Timofte
}

\begin{abstract}
Iuliana Simona Luca - Department of Biology, Faculty of Biology, Alexandru Ioan Cuza University, B-dul Carol I, no11, Iasi, Romania

Irina Dobrin - MD, PhD, psychiatrist, lecturer, "Grigore T. Popa" University of Medicine and Pharmacy, Iasi, Romania

Alin Ciobîcă - PhD, Department of Biology, Faculty of Biology, Alexandru Ioan Cuza University, Iasi, Romania, Academy of Romanian Scientists, Bucuresti, Center of Biomedical Research, Romanian Academy, Iasi

Alexandru Ungureanu - Psychologist, Faculty of Psychology, Alexandru Ioan Cuza University, Iasi, Romania

Daniel Timofte - Professor, MD, PhD, "Grigore T. Popa" University of Medicine and Pharmacy, Iasi, Romania
\end{abstract}

\section{ABSTRACT}

In the recent decades, the incidence of cardiovascular diseases, as well as endocrine and metabolic diseases, which are affecting the quality of human life, is constantly increasing. Currently, given that the prevalence of metabolic diseases, obesity and diabetes is constantly increasing worldwide, there is an increased interest in developing new therapies and in creating better experimental models for mimicking the complex human symptomatology. This could result in a faster diagnosis with lower cost, as well as in advances of the so-called personalized medicine. Among the animals that could be experimental models for these diseases, there is an increased interest in the zebrafish (Danio rerio), giving that the qualities that recommend it are its small size, the need for a small living space, relatively low costs of use, high homology to the human genome, high fertility and mostly the formation of the major organs at $\mathbf{2 4}$ hours after fertilization. In this way, the presence in zebrafish of all the key organs that are important and necessary for the complex metabolic control, as well as the similarities in lipid metabolism and the adipogenic pathway between zebrafish and mammals, could make this small organism an ideal tool for the study and the better understanding of adipogenesis, diabetes, obesity and the complex pathological processes which are 


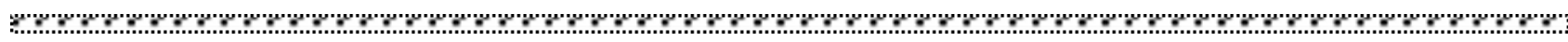
characterizing the metabolic diseases. This could have an increased relevance in the context of our previous work describing neuropsychiatric models in zebrafish (focusing for example on dementia), considering also the important connections that might exist between the general metabolic disorders and most of the neuropsychiatric-related manifestations.

\section{KEYWORDS:}

Metabolic syndrome, obesity, diabetes, zebrafish.

\section{INTRODUCTION}

The metabolic syndrome, generically called at the beginning by Gerald Reaven's, syndrome $\mathrm{X}$ in 1988, was then defined as an accumulation of abnormal disorders $(1,2)$. Syndrome $\mathrm{X}$, later becoming the subject of several researchers, was finally defined as a combination of 4 disorders (diabetes, blood pressure, obesity, hypertrigligeridemia) closely related to each other (3).

Regarding the endocrine and metabolic diseases, zebrafish is considered to have great potential in the investigation of thyroid diseases, thyroid hormones and defects related to their receptors, helped by the fact that the zebrafish, like the mammals, has molecular mechanisms and components related to thyroid axis (4). Moreover, knowing that the organ systems of zebrafish resemble those of humans, especially those related to metabolic control to regulate body energy homeostasis, which results in obesity, zebrafish has been used to study various diseases in the field of metabolic diseases such as obesity, diabetes, nonalcoholic fatty liver disease (NAFLD), nonalcoholic steatohepatitis (NASH), atherosclerosis and liver cancer (5) (6).

Thus, it was lately suggested that zebrafish can be used successfully in modeling these diseases because it has all the key organs to balance energy homeostasis and metabolism in mammals, as well as appetite regulation, insulin and lipid storage. (5) (6) (7) (8).

Diabetes, known as a syndrome with high blood glucose levels and as a consequence of metabolic imbalance, also affects the quality of human life and requires the creation of an experimental model on which this disease can be modeled. (8).

\section{METABOLIC SYNDROME}

As mentioned, the initially called Syndrome $\mathrm{X}$, went through several definitions: obesity, along with a fasting blood glucose $>100$ $\mathrm{mg} / \mathrm{dl}$, accompanied by high blood pressure, high triglycerides $>150 \mathrm{mg} / \mathrm{dl}$ and an increase in lipoproteins (Lower HDL) (9). Reaching another definition, practically an association of increased glucose with at least two other health problems: high blood pressure, increased plasma triglycerides, abdominal BMI $>30 \mathrm{~kg} / \mathrm{m}^{2}$ and microalbuminoria (9).

Finally, the European Insulin Resistance Study Group (EGIR) defined X syndrome as insulin resistance syndrome, along with 2 other factors: high plasma glucose, but not necessarily a person with diabetes, high triglycerides, low HDL, blood pressure. All definitions assigned to syndrome $\mathrm{X}$ show that the 4 disorders (diabetes, blood pressure, obesity and hypertriglyceridaemia) are related to each other (9).

Underlying the body's survival and functioning is the control of energy homeostasis between cells and tissues. When this homeostasis is disrupted in the body, the toxic accumulation of carbohydrates, proteins and lipids takes place. In diabetes, high blood sugar causes both micro- and macrovascular diseases (10), which in turn can cause strokes, heart attack, kidney failure, blindness and neuropathy (11) (12) (13). In conclusion, the metabolic syndrome must be understood at the system level precisely because of its multi-organ effects. 
Zebrafish has great potential for investigating thyroid diseases and everything related to them, because it has all the components related to the thyroid axis, similar to mammals; thus, by using transgenic lines, this model is suitable for developing new therapeutic approaches (4). It has also been observed that long-term exposure to environmental chemicals causes disorders similar to those caused by endocrine disorders. Chemicals that interfere with the components of the endocrine system are called endocrine disrupting components (EDC). Zebrafish can be used to understand related mechanisms and to detect EDC by applying biomarkers, specific genes and a transcriptomic platform (14).

The organ systems of zebrafish are similar to humans in terms of metabolic control for regulating body energy homeostasis, and for this reason zebrafish has been used to model metabolic diseases such as obesity, diabetes, NAFLD, NASH, atherosclerosis and liver cancer (5) (6). The basic metabolic mechanisms of zebrafish are similar to those of humans (15). Other similarities of zebrafish with humans consist in the development of the peripheral nervous system (16), and the development of adipose tissue takes place in both species, as well as the existence of similar genetic factors (17).

Metabolic disease is a consequence of the interaction of lifestyle, socio-economic factors and behavioral factors (18) (19) (20). Both energy metabolism by maintaining energy homeostasis and the microbiome can certainly affect metabolism (18) (19) (20). In zebrafish, organs such as the thyroid and endocrine pancreas develop within 48 hours dpf (days after fertilization) and have the role of secreting hormones essential for maintaining energy homeostasis. (21) (22) (23) (24), and the maintenance of metabolic homesostasis begins by regulating glucose. Returning to the influence of the microbiome on metabolism, a basic microbiome has been observed in zebrafish, and researchers have begun to study how infection naturally or induced alters the intestinal microbiota by disrupting carbohydrate and lipid homeostasis
(25) (26) (27) (28) (29) (30) (31) (32). Over time, zebrafish have been used in the study of many metabolic diseases, innate metabolic errors (33) (34) yper and hypothyroidism (35) (36), metabolic cancer (37), and in this review I will bring in discuss diabetes, obesity and dyslipidemia as the most common metabolic tubing (38) (39). So zebrafish can be a model for studying metabolic diseases due to functional preservation in lipid metabolism, adipose tissue biology, glucose structure and glucose homeostasis (40).

\section{OBESITY}

Obesity, a global health problem, is a disease that results from the interaction of genetic and environmental factors, characterized by increased fat storage in WAT (white adipose tissue). Causes of obesity include the quantity and quality of food consumed by individuals, as well as exposure to obesogens, a class of chemicals that disrupt the endocrine system, and their presence in early life affects adipogenesis and lipid metabolism (41) (42).

Obesity, the result of a positive balance when the energy ratio is higher than its expenditure, causes the organs involved in maintaining balance, mean the brain, liver and adipose tissue to interact to regulate this aspect. Due to the similarities with the human body, the zebrafish is used to study obesity (43) (44). Zebrafish is a suitable model to study metabolic dysfunction because it has digestive organs, adipose tissue and skeletal muscle, organs that regulate energy homeostasis and metabolism in mammals (45) (46).

In mammals there are 2 main classes of adipose tissue: brown adipose tissue (BAT) which dissipates energy and generates heat, and white adipose tissue (WAT) with the role of energy storage and regulation of energy balance (47). BAT consists of several drops of microvesicular lipids as well as many mitochondria that have the role of providing heat using lipids. WAT is a large unilocular lipid drop formed by the union of small lipid droplets that will be stored as a small energy reserve (48). Adult zebrafish contain WAT in the pancreatic, visceral, esophageal, mandibular, cranial, and tail fins (49). Being poikilothermic animals, they do not contain 
BAT, although they have been shown to have an approved coupling protein 1 (PCU 1) that can be associated with BAT in other species (50).

To better understand the physiological changes of an organism affected by obesity, zebrafish are used to monitor adipogenesis, from egg fertilization to larval stage, precisely because zebrafish larvae develop outside the mother's body and due to the optical transparency of them. Thus, with the help of appropriate tools, defects in the absorption, transport and arrangement of lipids can be detected (51) (52). Zebrafish also contain cells that specialize in the absorption and processing of lipids (eg, intestinal enterocytes, fat-storing adipocytes, liver hepatocytes, and pancreatic acinar cells) (53) (54). Adipocytes that form in fish larvae can be observed with the help of dyes: Sudanophilic dye Oil Red O (ORO), Sudan Nile Red, or Lipid Green (55), and to observe the transport of fatty acids are used BODIPY lipophilic floroflor by injection yolk, from fish food, the latter reaching the circulatory system very quickly, lasts about 3 hours (56).

Zebrafish can be considered a suitable model for human lipid metabolism because functions such as regulating appetite (by the presence in the hypothalamus of appetite circuits) of insulin (through the pancreas) and lipid storage are well preserved (57) (58) ( 59). Excess nutrients increase plasma TGL levels and the appearance of hepatic steatosis (60) as well as the presence in zebrafish of horses that regulate lipid metabolism: SREBF 1, P PAR S, NR 1 N 3, LEP (60) make it a suitable model .

The preservation of these metabolic pathways that intervene in the differentiation of adipocytes energy homeostasis (61) and cholesterol metabolism make zebrafish an ideal model for human lipid metabolism (62). Obesity caused by the creation of a prolonged imbalance between calories entered and insufficient energy expenditure, is characterized by adipose tissue hypertrophy and hyperplasia. Obesity occurs practically when the excess energy, stored in the form of lipid droplets, is deposited in both adipose and non-adipose tissues (63) (64).

Excess nutrients cause adipocyte hypertrophy and hyperplasia in adipose tissue; Among the cells that inflame adipose tissue are macrophages and pro-inflammatory molecules: tumor necrosis factor (TNF- $\alpha$ ), interleukin-6 (IL-6), monocytic chemoattractant protein (MCP-1) (65) (66) (67). Adipocytes and macrophages interact and thus inflammatory adipocytokines decrease, leading to complications associated with obesity. In many organs it all causes some metabolic disorders, insulin resistance, diabetes, cardiovascular disease, stroke and even some cancers (68) (69). It has been shown that in order to assess the development of comorbidities related to obesity, the distribution of fat in a body is more important than the total amount of fat (70) (71). When adipose tissue grows, plasma free fatty acids (FAA) are released and in obese patients it forms a link between obesity and metabolic syndrome by promoting lipotoxicity in the liver and muscles, by altering the action of insulin and causing non-alcoholic fatty liver disease (NAFLD) (72).

Knowing that the hypothalamus is the site of appetite circuits (73), leptin receptors and melanocortin system proteins (74) (75) we can highlight the similarities of fish with humans in this regard. Intracerebroventricular administration of neuroactive peptides (NPY) has also been shown to definitely stimulate food intake, and administration of CART (regulated cocaine and amphetaminetranscription) of melanocortin peptides and CRF (corticotropin-releasing factor) inhibits feeding (76). A zebrafish model for obesity can be created by chromosomal translocation, which suppresses central melanocortin receptors, knowing that the central melanocortin system (CMS) controls and regulates energy homeostasis. It contains propriomelanocortin (POMC), peptides and agouti-bound peptide (AgRP). Zebrafish following this chromosomal translocation increase in weight due to the high content of triglycerides (TGL), due to increased expression of AgRP, an endogenous 
antagonist of melanocortin and due to visceral fat accumulation (36) (77).

Leptin, the main adipostatic factor, is a hormone that informs the brain about the total energy stored as TGL in fat cells; and by regulating the amount of adipose tissue in the body, by inhibiting food intake, by stimulating energy expenditure, reducing body weight and fat percentage intervenes to maintain euglycemic status (78). Leptin leads to the onset of hepatic steatosis and the onset of insulin resistance (79). Deficiency of this hormone causes the onset of deep hyperphagia and obesity, infertility and diabetes. The difference is that in zebrafish the leptin receptor is expressed in the liver and other tissues, and not in adipose tissue as in humans, and the deficiency of receptors in zebrafish larvae causes an increase in the number of beta cells and insulin mRNA levels, and larval zebrafish in response to a fatty diet may have beta cell hyperplasia or peripheral insulin resistance, so it can be said that leptin has a major role in maintaining glucose homeostasis and a secondary role as an adipostatic factor (80).

Zebrafish, like mammals, have white adipose tissue, initially made up of several small drops of lipids, and as they develop, they turn into a single large drop of lipids (81). Visceral adiposity is considered to be a critical risk factor for other metabolic diseases and T2DM (82). Zebrafish contain lipid deposits in visceral, intramuscular and subcutaneous adipocytes (83) and can assess the degree of metabolic disorders related to obesity. In humans, these quantitative measures consist of the calculation of body mass index and quantitative computed tomography (CT), and in fish lipophilic dyes are used: red Nile, oil Red O and Sudan Black B (84) (85). With zebra larvae having optical transparency, the researchers developed screens based on live imaging and fluorescence to study digestive physiology or lipid metabolism. Nile red has been used to quantify intracellular neutral lipid droplets and for vivid imaging (86) as well as to purify adipose tissue (87). In addition, a variety of fatty acid analogs and fluorescent lipid tracers are available, including BODIPY cholesterol analogs and fluorescence reports such as PED 6 for monitoring the metabolism and distribution of exogenous lipids in live zebrafish (88) (89). Micro CT 3D is also available for this small animal and allows the measurement of total adipocyte tissue volume as well as various fat deposits (90). Recently, Landgrof et al., compared the methodology for quantifying the body fat mass of zebrafish using MR imaging (MRI) and 4 in 1 Echo MRI (Echo MRI tm) (91). These methods provide accurate measurements of zebrafish adiposition and provide means for longitudinal monitoring.

It was also showed that a high-fat diet given to zebrafish larvae increases adiposity, and in adult zebrafish it causes hepatosteatosis, hypertriglyceridemia, and high BMI (39) (92). One of the methods of inducing obesity is to administer excess fat immediately after 5 days after fertilization. Early larvae do not have WAT (93), in which case lipid droplets accumulate in the bloodstream, and the amount of whole larval triacylglycerol is used as an indicator to quantify the progression of obesity (94) (95). A high-fat diet consists of administering egg yolk (95).

Zebrafish larvae begin to eat 5 days after fertilization (dpf), until then they absorb the essential fats, cholesterol and triacylglycerol provided by a sac of maternal yolk (96). At 5 dpf the lipids become visible in several tissues, with the formation of a small deposit in hepatocytes; instead, the first signs of adipogenesis can be seen at $8 \mathrm{dpf}$ in the visceral cavity, close to the pancreas. Adipocytes appear in the pancreas of larvae at 12 dpf (96). To highlight adipocytes, at 15 dpf, red Nile dye is used; $15 \mathrm{dpf}$ being the day when the adipocytes in the visceral area (internal intra-abdominal and surrounding organs become visible (97); a location associated in humans with risk factors for the development of type 2 diabetes mellitus (T2DM) (98) (99). The number of adipocytes correlates with the size of the larvae, rather than with their age; thus, it was observed that at $17 \mathrm{dpf}$ the larvae have WAT in the pancreatic and visceral area, and at 20-22 dpf, 
\%

subcutaneous and cranial adipocytes develop, depending on the size (93).

There is also an increase in microsomal triglyceride transfer protein (MTP) mRNA levels in the proximal intestine and liver, following a high-fat diet (90). MTP has a $54 \%$ identity with human MTP and is involved in the breakdown of lipoproteins in the born ApoB, and these ApoB-MTP complexes can prevent lipid degradation by proteasomes and increase plasma lipid levels. ApoB levels increased in response to overeating (100) (101).

The high degree of conservation in the distribution and formation of adipose tissue in zebrafish compared to mammals make it a suitable model to study obesity.

\section{DIABETES}

Diabetes is a syndrome characterized by elevated blood glucose levels (hyperglycemia) and metabolic imbalance (102).

Chronic blood glucose is the major biochemical diagnostic parameter observed in the two major forms of diabetes: type 1 or insulin-dependent diabetes, caused by autoimmune destruction of insulin-producing pancreatic beta cells, and T2DM or noninsulin-dependent characterized by insulin insensitivity (102).

The development of the pancreas in the organs of vertebrates often involves a twostage process. First, the formation of a functionally immature organ during embryogenesis, which is followed by differentiation into mature form (103) (104). The second step most often occurs during the postembryonic / postnatal period, when the concentration of plasma thyroid hormone (TH) becomes high. In addition, mammalian weaning, frog metamorphosis, and the larvaljuvenile transition of the zebrafish have been proposed to be functionally equivalent events during postembryonic development, based on cellular and molecular events in their digestive organs, including the pancreas, and increase in plasma $\mathrm{TH}$ concentration during these periods (103) (104).
To understand exactly when and where $\mathrm{TH}$ works in the pancreas, the thyroid is ablated when treated with metronidazole. Thyroid ablation leads to loss of endogenous TH (105). A transgenic line can be used to perform conditioned $\mathrm{TH}$ during the transition from larvae to the juvenile transition. After thyroid ablation, insulin expression was decreased and glucagon expression was loaded, followed by increased blood glucose during the transition from larval to juvenile. Decreased insulin secretion and increased glucagon secretion and the resulting increase in blood glucose continued in adult fish. The TH treatment of adult thyroid fish increased insulin secretion and reduced glucagon secretion and reduced blood glucose levels. These results suggest that $\mathrm{TH}$ is important to generate $\alpha$ and $\beta$ cells and to maintain their maturation. In addition, glucose sensitivity was found to be improved in both $\alpha$ and $\beta$ cells after T3 treatment (106). Thus, TH can regulate $\alpha$ and $\beta$ cells in cell maturation by increasing glucose sensitivity (105).

The pancreas is an organ with two sets of functions: those related to the digestive system (acinar cells and ductal cells), and those of the endocrine system (islets). Several phylogenetic analyzes suggest that the digestive system and the endocrine system evolved differently (107) and that the single unified pancreas developed as a new organ through the fusion of endocrine and digestive parts during fish evolution (107).

The zebrafish pancreas comes from two progenitor domains called the dorsal bud (DB) and the ventral bud (VB). However, unlike dorsal and ventral pancreatic buds in mammals, DB and VB in zebrafish have distinct differentiation potentials (108). DB is formed within 24 hours after fertilization (HPF) and consists of early endocrine cells grouped to form the main islet. VB arises from the intestinal tract after $34 \mathrm{dpf}$ and these cells migrate to swallow the main islet (108). The endocrine compartment consists of alpha cells that secrete glucagon, beta cells that produce insulin, gamma cells that produce somatostatin, epsilon cells that produce ghrelin, and pancreatic polypeptides that 
produce PP (109) (110). In addition to the pancreas, the development and function of other organ systems involved in glucose homeostasis, including the brain, liver, adipose tissue and skeletal muscle are also preserved (111). Preservation of pancreatic structure and system glucose homeostasis makes zebrafish useful for identifying new targets in pancreatic-related diseases such as diabetes.

Pancreatic $\beta$ cells secrete insulin in response to high glucose levels. In $\beta$ cells in mammals under high glucose conditions, this one moves into $\beta$ cells through the glucose transporter, GLUT2. Beta cells then produce more ATP, which increases the ATP / ADP ratio through glucose metabolism. Increasing the ATP / ADP ratio stimulates the closure of the ATPdependent potassium channel (KAtp), subsequently evoking the depolarization of $\beta$ cells that leads to the activation of $2+$ channels that stimulate insulin secretion. Like mammals, GLUT 2 is expressed in pancreatic zebrafish $\beta$ cells. In addition, KAtp and $\mathrm{Ca} 2+$ channels regulate insulin secretion according to blood glucose levels (112),(113). These indicate that the pancreatic $\beta$ cells of zebrafish function in the same way as other vertebrates. On the other hand, these investigations were performed using main islets, but not with secondary islets. The molecular mechanisms underlying the secondary development of islets in zebrafish is similar to that of the development of mammalian islets. Thus, determining the functional differences between the main islets and the secondary islets could become important to understand how vertebrates acquired functional islets.

T1DM is an organ-specific autoimmune disease caused by the destruction of insulinproducing pancreatic beta cells by $\mathrm{T}$ cells (114). T2 DM is a metabolic disease associated with insulin resistance. Hyperglycemia in T2DM is initially accompanied by compensatory hyperinsulinemia, but as the disease progresses oxidative stress triggers beta cell apoptosis, and the amount of insulin produced by the pancreas gradually decreases (115). T2 DM is an often associated lifestyle disease. with obesity and considered part of the metabolic syndrome (116). T2DM is accompanied by chronic inflammation and oxidative stress (117) and patients often develop non-alcoholic fatty liver disease (118). Insulin is the cause of hyperglycemia in T1 DM. The most common treatment for this form of the disease is insulin injection. Antidiabetic drugs for T2DM can directly target hyperglycemia by promoting the release of insulin from beta cells in the early stages of the disease by improving the insulin sensitivity of target cells in various ways or by slowing the digestion of carbohydrates after meals. T2DM patients can also improve their health by reducing obesity, inflammation and oxidative stress.

Deficiency of glucose, the main fuel of the brain, leads to coma, convulsions causing permanent damage to the brain. Glucose reaches the brain through $\mathrm{CBF}$ (119) cerebral blood flow through endothelial cells, to the blood-brain barrier (BBB) (120) and eventually to glial cells through facilitated diffusion. Glucose is transported to glial cells and neurons by GLUT 7 carriers. Although insulin alters glucose metabolism in the CNS (121) it is not the main mechanism in the brain for neuronal absorption. But insulin influences activities such as neuronal growth and survival, synaptic plasticity, neurotransmitter release, tubulin activity, cognitive improvement of memory, learning (123).

Destruction of pancreatic beta cells is the leading cause of T1 DM and a consequence of T2DM progression. The toxic glucose analogue of alloxan is well known for its use in rodent diabetes models and has been used successfully in wild zebrafish larvae along with staining of the fluorescent analog 2NBDG for one hour and using a fluorescent microscope (124) a green fluorescence is obtained. For wild-type larvae, an alternative method of visualizing the pancreas is to use fluorescent conjugated antibodies against insulin or glucagon (125).

Glucose transporters (GLUT) in zebrafish have a structure and tissue distribution similar 
r

to that of mammals (126) (127). Fluorescent analogues of glucose 2-NBDG and GB-2 Cy 3 are both substrates known for GLUT and have been used to monitor glucose uptake in zebrafish larvae. Increased uptake of 2 NBDG could be inhibited by the glucose transporter inhibitor () and reduced in the presence of excess D-Glucose to illustrate that uptake of 2 NBDG in zebrafish occurs through GLUTs in similar to that of mammalian glucose (129).

The pancreas of the zebrafish is very similar to that of humans in terms of cell types, as well as the secretion of hormones and digestive enzymes. Regulation of zebrafish genes for insulin, glucagon, and other proteins involved in glucose metabolism has also been shown to be similar in the two species (130). Increased endogenous glucose levels in zebrafish larvae are associated with a increased expression of the gluconeogenic regulatory enzyme PEPCK (131). The major regulatory mechanism for this enzyme is the activation of expression by cortisone and glucagon and inhibition of glucagon receptor signaling lead to a reduction in PEPCK which in turn improved insulin sensitivity and reduced blood glucose in models with severe insulin resistance (132). In addition, hyperglycemia and excessive gluconeogenesis are present in all forms of diabetes. (133).

Direct measurement of in vivo glucose levels in larvae can also be used as an indicator of glucose homeostasis reflecting the net activity of glycolysis and gluconeogenesis (134). Inflammation is triggered by numerous stimuli (microbiological, physical and chemical) which activates the immune system and recruits immune cells. It is accompanied by the production of inflammatory mediators such as proinflammatory cytokines (interleukin -6, IL-6, IL-8, IL-1beta, macrophage granulocyte colony stimulating factor and tumor necrosis factor alpha (135).

Inflammation and oxidative pathways are interconnected to form a positive feedback loop. Immune cell recruitment and the secretion of cytokines and chemokines lead to the production of reactive oxygen species (ROS) and reactive nitrogen species (NOS).
During diabetes, inflammation in wild zebrafish larvae was achieved by exposure to high concentrations of glucose or fructose (136).

In fact, this mini-review of ours could open the discussion on the obvious connections that might exist between the digestive and gastrointestinal-metabolic component that is associated with the neuropsychiatric one (137, 138), considering the latest expertise of our group in this area (139), as well as the social implications in this context $(140,141)$, and of course the neurological and psychiatric manifestations related to the general metabolic disorders, in the context of the oxidative stress (another important expertise and perspective of our group -142) or not (143-146).

We could also mention in this context, the developing of the techniques for glucose homeostasis in zebrafish, as many transgenic strains of zebrafish with fluorescent protein expression have been used to study pancreatic development and glucose homeostasis in living vertebrates (148).

Thus, methods for zebrafish pancreatic function have been established, including postprandial blood glucose measurement and glucose tolerance tests as well as pancreatic dissection techniques and islet cell culture (150).

In larvae, blood collection for glucose measurement is not a viable methodology, but free glucose in whole larvae can be measured by a coupled enzyme fluorescent test (151). For adult zebrafish, the small size $(3-4 \mathrm{~cm})$ makes blood collection difficult. However, several protocols have been developed for blood collection: lateral incision in the dorsal aorta, decapitation and tail ablation, although these methods require animal sacrifice (153).

Measuring insulin function was a major challenge in this context. As surrogate indicators, insulin mRNA levels can be determined directly by qPCR and insulin promoter activity can be determined indirectly by measuring EGFP signal strength in Tg (- 
\% \%

1.oins.EGFP) over zebra (154). Insulin sensitivity can also be assessed by intraperitoneal injection of insulin into hyperglycemic zebrafish (156). Also, young fish (4-11 months) acclimatize more easily to the glucose exposure protocol compared to older fish (1-3 years) so they showed a transient hyperglycemia, but persistent hyperglycemia can be achieved in young zebrafish by gradually increasing glucose concentration (157).

\section{CONCLUSIONS}

In this way, the presence in zebrafish of all the key organs that are important and necessary for the complex metabolic control, as well as the similarities in lipid metabolism and the adipogenic pathway between zebrafish and mammals, could make this small organism an ideal tool for the study and the better understanding of adipogenesis, diabetes, obesity and the complex pathological processes which are characterizing the metabolic diseases. This could have an increased relevance in the context of our previous work describing neuropsychiatric models in zebrafish (focusing for example on dementia), considering also the important connections that might exist between the general metabolic disorders and most of the neuropsychiatric-related manifestations.

\section{ACKNOWLEDGEMENTS AND DISCLOSURES}

The authors state that there are no declared conflicts of interest regarding this paper.

\section{REFERENCES}

1. Chakraborty C, Hsu CH, Wen ZH, Lin CS, Agoramoorthy G. Zebrafish: a complete animal model for in vivo drug discovery and development. Curr Drug Metab. (2009) 10:116-24.

2 Gerald, M. R. 2001. Syndrome X: A Short History. Ochsner. J. 3: 124- 125.

3. Vancampfort D., Stubbs B., Mitchell, A.J., De Hert, M, Wampers, M., Ward v, P.B., Rosenbaum, S. and Corell, C.U. 2015. Risk of metabolic syndrome and its components in people with schizophrenia and related psychotic disorders, bipolar disorder and major depressive disorder: a systematic review and meta-analysis. World Psichiatry 14: 339-47.

4. Ding Y, Liu W, Deng Y, Jomok B, Yang J, Huang W, Clark KJ, Zhong TP, Lin X,Ekker SC, Xu X. Trapping cardiac recessive mutants via expression-based insertional mutagenesis screening. Circ Res 112: 606-617, 2013.

5. Cox AG, Hwang KL, Brown KK, Evason KJ, Beltz S, Tsomides A, O’Connor K, GalliGG, Yimlamai D, Chhangawala S, Yuan M, Lien EC, Wucherpfennig J, Nissim S,Minami A, Cohen DE, Camargo FD, Asara JM, Houvras Y, Stainier DY, Goessling W.Yap reprograms glutamine metabolism to increase nucleotide biosynthesis and enableliver growth. Nat Cell Biol 18: 886-896, 2016.

6. Ding Y, Sun X, Huang W, Hoage T, Redfield M, Kushwaha S, Sivasubbu S, Lin X, Ekker S,Xu X. Haploinsufficiency of target of rapamycin attenuates cardiomyopathies in adult zebrafish. Circ Res 109: 658 - 669, 2011.

7. Arjmand B, Goodarzi P, Mohamadi-Jahani F, Falahzadeh K, Larijani B. Personalized regenerative medicine. Acta medica Iranica. (2017) 55:144-9.

8. Oku H, Umino T. Molecular characterization of peroxisome proliferator- activated receptors (PPARs) gene expression in the differentiating adipocytes of red sea bream Pagrus major. Comp Biochem Physiol B Biochem Mol Biol. 2008;151:268-277.

9. Khosravi-Boroujeni, H., Ahmed, F., Sadeghi, M., Roohafza, H., Talaei, M., 15 Dianatkhah, M., Pourmogaddas, A. and Sarrafzadegan, N. 2015. Does the impact of 16 metabolic syndrome on cardiovascular events vary by using different definitions? 17 BMC Public Health 15: 1313.

10. Lozano R, Naghavi M, Foreman K, Lim S, Shibuya K, Aboyans V, Abraham J, Adair T, et al. Global and regional mortality from 235 causes of death for 20 age groups in 1990 and 2010: a systematic analysis for the Global Burden of Disease Study 2010. Lancet 380: 2095-2128.

11. Collaborators GBD, Forouzanfar MH, Afshin A, Alexander LT, Anderson HR, BhuttaZA, Biryukov S, Brauer M, et al. Global, regional, and national comparative risk assessment of 79 behavioural, environmental and occupational, and metabolic risks or clusters of risks, 1990-2015: a systematic analysis for the Global Burden of Disease Study 2015. Lancet 388: 1659-1724, 2016.

12. Murray CJ, Vos T, Lozano R, Naghavi M, Flaxman AD, Michaud C, Ezzati M, ShibuyaK, et al. Disability-adjusted life years (DALYs) for 291 diseases and injuries in 21 regions, 1990-2010: a systematical analysis for the Global Burden of Disease Study 2010. Lancet 380: 2197-2223. 


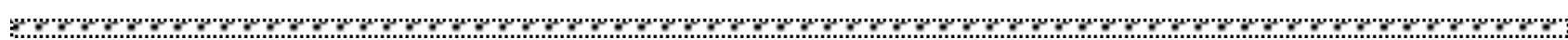
13. Vos T, Flaxman AD, Naghavi M, Lozano R, Michaud C, Ezzati M, Shibuya K, SalomonJA, et al. Years lived with disability (YLDs) for 1160 sequelae of 289 diseases and injuries 1990-2010: a systematic analysis for the Global Burden of Disease Study2010. Lancet 380: 2163-2196.

14. Ding Y, Long PA, Bos JM, Shih YH, Ma X, Sundsbak RS, Chen J, Jiang Y, Zhao L, Hu X,Wang J, Shi Y, Ackerman MJ, Lin X, Ekker SC, Redfield MM, Olson TM, Xu X. A modifier screen identifies DNAJB6 as a cardiomyopathy susceptibility gene. JCI Insight 1: 14, 2016.

15. Dong PD, Munson CA, Norton W, Crosnier C, Pan X, Gong Z, Neumann CJ, StainierDY. Fgf10 regulates hepatopancreatic ductal system patterning and differentiation. Nat Genet 39: 397- 402, 2007.

16. Dooley K, Zon LI. Zebrafish: a model system for the study of human disease. Curr Opin Genet Dev 10: 252-256, 2000 .

17. Doyle EL, Booher NJ, Standage DS, Voytas DF, Brendel VP, Vandyk JK, Bogdanove AJ.TAL Effector-Nucleotide Targeter (TALE-NT) 2.0: tools for TAL effector design and target prediction. Nucleic Acids Res 40: W117-W122, 2012.

18. Eames SC, Philipson LH, Prince VE, Kinkel MD. Blood sugar measurement in zebrafish reveals dynamics of glucose homeostasis. Zebrafish 7: 205-213, 2010

19. Kinkel MD, Eames SC, Philipson LH, Prince VE. Intraperitoneal injection into adult zebrafish. J Vis Exp 42: 2126 , 2010.

20. Marín-Juez R, Jong-Raadsen S, Yang S, Spaink HP. Hyperinsulinemia induces insulin resistance and immune suppression via Ptpn6/Shp1 in zebrafish. J Endocrinol 222:229-241, 2014.

21. Houbrechts AM, Delarue J, Gabriëls IJ, Sourbron J, Darras VM. Permanent de iodinase type 2 deficiency strongly perturbs zebrafish development, growth, and fertility. Endocrinology 157: 3668-3681, 2016.

22. Jurczyk A, Roy N, Bajwa R, Gut P, Lipson K, Yang C, Covassin L, Racki WJ, RossiniAA, Phillips N, Stainier DY, Greiner DL, Brehm MA, Bortell R, diIorio P. Dynamic glucoregulation and mammalian-like responses to metabolic and developmenta ldisruption in zebrafish. Gen Comp Endocrinol 170: 334-345, 2011.

23. Ober EA, Field HA, Stainier DY. From endoderm formation to liver and pancreas development in zebrafish. Mech Dev 120: 5-18, 2003.

24. Opitz R, Maquet E, Huisken J, Antonica F, Trubiroha A, Pottier G, Janssens V, Costagliola S. Transgenic zebrafish illuminate the dynamics of thyroid morphogenesis and its relationship to cardiovascular development. Dev Biol 372 : 203-216, 2012

25. Bates JM, Akerlund J, Mittge E, Guillemin K. Intestinal alkaline phosphatase detoxifieslipopolysaccharide and prevents inflammation in zebrafish in response to the gutmicrobiota. Cell Host Microbe 2: 371-382, 2007.

26. Falcinelli S, Picchietti S, Rodiles A, Cossignani L, Merrifield DL, Taddei AR, MaradonnaF, Olivotto I, Gioacchini G, Carnevali O. Lactobacillus rhamnosus lowers zebrafish lipid content by changing gut microbiota and host transcription of genes involved in lipid metabolism. Sci Rep 5: 9336, 2015.

27. Falcinelli S, Rodiles A, Unniappan S, Picchietti S, Gioacchini G, Merrifield DL, CarnevaliO. Probiotic treatment reduces appetite and glucose level in the zebrafish model. SciRep 6: 18061, 2016.

28. Hill JH, Franzosa EA, Huttenhower C, Guillemin K. A conserved bacterial protein induces pancreatic beta cell expansion during zebrafish development. eLife 5: e20145,2016.

29. Pham LN, Kanther M, Semova I, Rawls JF. Methods for generating and colonizing notobiotic zebrafish. Nat Protoc 3: 1862-1875, 2008.

30. Rawls JF, Mahowald MA, Ley RE, Gordon JI. Reciprocal gut microbiota transplants from zebrafish and mice to germ-free recipients reveal host habitat selection. Cell127: 423-433, 2006.

31. Rawls JF, Samuel BS, Gordon JI. Gnotobiotic zebrafish reveal evolutionarily conservedresponses to the gut microbiota. Proc Natl Acad Sci USA 101: 4596-4601, 2004.

32. Wong S, Stephens WZ, Burns AR, Stagaman K, David LA, Bohannan BJ, Guillemin K, Rawls JF. Ontogenetic differences in dietary fat influence microbiota assembly in thezebrafish gut. MBio 6: e00687-e15, 2015.

33. Matthews RP, Lorent K, Mañoral-Mobias R, Huang Y, Gong W, Murray IV, Blair IA,Pack M. TNFalpha-dependent hepatic steatosis and liver degeneration caused $\mathrm{b}$ mutation of zebrafish S-adenosylhomocysteine hydrolase. Development 136: 865-875, 2009.

34. Paardekooper Overman J, Yi JS, Bonetti M, Soulsby M, Preisinger C, Stokes MP, HuiL, Silva JC, Overvoorde J, Giansanti P, Heck AJ, Kontaridis MI, den Hertog J, BennettAM. PZR coordinates Shp2 Noonan and LEOPARD syndrome signaling in zebrafish and mice. Mol Cell Biol 34: 2874-2889, 2014.

35. Houbrechts AM, Delarue J, Gabriëls IJ, Sourbron J, Darras VM. Permanent deiodinase type 2 deficiency strongly perturbs zebrafish development, growth, and fertility. Endocrinology 157: 3668-3681, 2016.

36. Zada D, Tovin A, Lerer-Goldshtein T, Appelbaum L. Pharmacological treatment and BBB-targeted genetic therapy for MCT8-dependent hypomyelination in zebrafish. DisModel Mech 9: 1339-1348, 2016.

37. Cox AG, Hwang KL, Brown KK, Evason KJ, Beltz S, Tsomides A, O’Connor K, GalliGG, Yimlamai D, Chhangawala S, Yuan M, Lien EC, Wucherpfennig J, Nissim S,Minami A, Cohen DE, Camargo FD, Asara JM, Houvras Y, Stainier DY, Goessling W.Yap reprograms glutamine metabolism to increase nucleotide biosynthesis and enableliver growth. Nat Cell Biol 18: 886 - 896, 2016.

38. Collaborators GBD, Forouzanfar MH, Afshin A, Alexander LT, Anderson HR, BhuttaZA, Biryukov S, Brauer M, et al. Global, regional, and national comparative risk assessment of 79 behavioural, environmental and occupational, and 


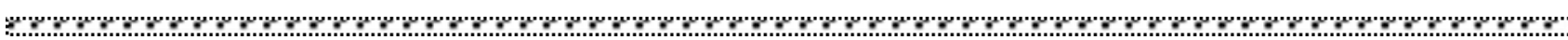
metabolic risks or clusters of risks, 1990-2015: a systematic analysis for the Global Burden of Disease Study 2015. Lancet 388: 1659-1724, 2016

39. Wang G, Rajpurohit SK, Delaspre F, Walker SL, White DT, Ceasrine A, Kuruvilla R, LiRJ, Shim JS, Liu JO, Parsons MJ, Mumm JS. First quantitative high-throughput screen in zebrafish identifies novel pathways for increasing pancreatic cell mass. eLife 4:08261, 2015.

40. Zang L, Maddison LA, Chen W. Zebrafish as a model for obesity and diabetes. Front Cell Dev Biol. (2018) 6:91.

41.Tingaud-Sequeira, A.; Ouadah, N.; Babin, P.J. Zebrafish obesogenic test: A tool for screening molecules that target adiposity. J.Lipid Res. 2011, 52, 1765-1772.

42. den Broeder, M.J.; Moester, M.J.B.; Kamstra, J.H.; Cenijn, P.H.; Davidoiu, V.; Kamminga, L.M.; Ariese, F.; de Boer, J.F.; Legler, J.Altered Adipogenesis in Zebrafish Larvae Following High Fat Diet and Chemical Exposure Is Visualised by Stimulated Raman Scattering Microscopy. Int. J. Mol. Sci. 2017, 18, 894.

43. Kleinert, M.; Clemmensen, C.; Hofmann, S.M.; Moore, M.C.; Renner, S.; Woods, S.C.; Huypens, P.; Beckers, J.; de Angelis, M.H.;Schurmann, A.; et al. Animal models of obesity and diabetes mellitus. Nat. Rev. Endocrinol. 2018, 14, $140-162$.

44. Khneizer, G.; Rizvi, S.; Gawrieh, S. Non-alcoholic Fatty Liver Disease and Diabetes Mellitus. In Advances in Experimental Medicine and Biology; Springer: New York, NY, USA, 2020; pp. 1-24.

45. Lieschke, G. J., and Currie, P. D. (2007). Animal models of human disease:zebrafish swim into view. Nat. Rev. Genet. 8, 353-367.

46. Schlegel, A., and Stainier, D. Y. (2007). Lessons from "lower" organisms: what worms, flies, and zebrafish can teach us about human energy metabolism. PLoSGenet. 3:e199.

47. Minchin JE, Rawls JF. In vivo analysis of white adipose tissue in zebrafish. Methods Cell Biol. 2011;105:63-86

48. Gesta, S.; Tseng, Y.H.; Kahn, C.R. Developmental origin of fat: Tracking obesity to its source. Cell 2007, 131, 242256.

49. Imrie, D.; Sadler, K.C. White adipose tissue development in zebrafish is regulated by both developmental time and fish size. Dev.Dyn. 2010, 239, 3013-3023.

50. Minchin, J.E.; Rawls, J.F. In vivo analysis of white adipose tissue in zebrafish. Methods Cell Biol. 2011, 105, 63-86 51. Brand M, Granato M, Nüsslein-Volhard C. Keeping and raising zeb-rafish. In: Nüsslein-Volhard C, Dahm R, eds.Zebrafish. Oxford, UK:Oxford University Press; 2002:7-37

52. Anderson JL, Carten JD, Farber SA. Zebrafish lipid metabolism:from mediating early patterning to the metabolism of dietary fat and cholesterol. Methods Cell Biol. 2011;101:111-141

53. Hölttä-Vuori M, Salo VT, Nyberg L, et al. Zebrafish: gaining popularity in lipid research. Biochem J. 2010;429:235-242.

54. Wallace KN, Akhter S, Smith EM, Lorent K, Pack M. Intestinal growth and differentiation in zebrafish. Mech Dev. 2005; $122: 157-173$

55. Flynn EJ, Trent CM, Rawls JF. Ontogeny and nutritional control of adipogenesis in zebrafish (Danio rerio). J Lipid Res. 2009;50:1641-1652.

56. Lee JH, So JH, Jeon JH, et al. Synthesis of a new fluorescent small molecule probe and its use for in vivo lipid imaging. Chem Commun(Camb). 2011;47:7500-7502

57. Elo, B., Villano, C. M., Govorko, D., and White, L. A. (2007 ). Larval zebrafish as a model for glucose metabolism: expression of phosphoenolpyruvatecarboxykinase as a marker for exposure to anti-diabetic compounds. $J$. Mol.Endocrinol. 38, 433-440.

58. Flynn, E. J. III, Trent, C. M., and Rawls, J. F. (2009). Ontogeny and nutritional control of adipogenesis in zebrafish (Danio rerio). J. Lipid Res. 50, 1641-1652.

59. Nishio, S., Gibert, Y., Berekelya, L., Bernard, L., Brunet, F., Guillot, E., et al. (2012).Fasting induces CART downregulation in the zebrafish nervous system in a cannabinoid receptor 1-dependent manner. Mol. Endocrinol. 26, 13161326.

60. Oka, T., Nishimura, Y., Zang, L., Hirano, M., Shimada, Y., Wang, Z., et al. (2010).Diet-induced obesity in zebrafish shares common pathophysiological path ways with mammalian obesity. BMC Physiol. 10:21.

61. Den Broeder, M. J., Kopylova, V. A., Kamminga, L. M., and Legler, J.(2015). Zebrafish as a model to study the role of peroxisome proliferating-activated receptors in adipogenesis and obesity. PPAR Res. 2015:358029.

62. Schlombs, K., Wagner, T., and Scheel, J. (20 0 3). Site-1 protease is required for cartilage development in zebrafish. Proc. Natl. Acad. Sci. U.S.A. 100,14024-14029.

63. Milani GP, Silano M, Pietrobelli A, Agostoni C. Junk food concep t:seconds out. Int J Obes (Lond) . 2017;41:669671

64. Kopelman P. Health risks associated with overweight and obesity. Obes Rev. 2007;8:13-17

65. Kang YE, Kim JM, Joung KH, et al. The Roles of adipokines, proinflammatory cytokines, and adipose tissue macrophages in obesity-associated insulin resistance in modest obesity and early metabolic dysfunction. PLoS One. 2016;11:e0154003.

66. Hotamisligil GS. Inflammation and metabolic disorders. Nature.2006;444:860-867.

67. Weisberg SP, McCann D, Desai M, Rosenbaum M, Leibel RL, Fer-rante AW Jr. Obesity is associated with macrophage accumulationin adipose tissue. J Clin Invest . 2003;112:1796-1808

68. Rocha VZ, Libby P. Obesity, inflammation, and atherosclerosis. NatRev Cardiol. 2009;6:399-409. 


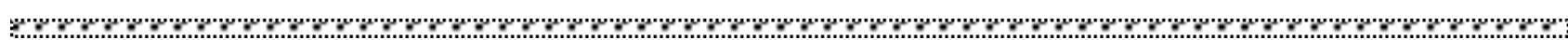
69. Mokdad AH, Ford ES, Bowman BA, et al. Prevalence of obesity, diabetes, and obesity-related health risk factors, 2001. JAMA.2003;289:76-79.

70. Anate M, Olatinwo A, Omesina A. Obesity - an overview. West AfrJ Med. 1998;17:248-254.

71. Després JP, Lemieux I, Bergeron J, et al. Abdominal obesity and the metabolic syndrome: contribution to global cardiometabolic risk. Arterioscler Thromb Vasc Biol. 2008;28:1039-1049.

72. Kopelman P. Health risks associated with overweight and obesity. Obes Rev. 2007;8:13-17.

73. Overton, J. M. (2010). Phenotyping small animals as models for the human metabolicsyndrome: thermoneutrality matters. Int. J Obes. 34 Suppl. 2, S53-S58.

74. Liu, Q., Chen, Y., Copeland, D., Ball, H., Duff, R. J., Rockich, B. and Londraville, R. L.(2010). Expression of leptin receptor gene in developing and adult zebrafish. Gen.Comp. Endocrinol. 166, 346-355.

75. Zhang, C., Forlano, P. M. and Cone, R. D. (2012). AgRP and POMC neurons are hypophysiotropic and coordinately regulate multiple endocrine axes in a larval teleost. Cell Metab. 15, 256-264.

76. Kawauchi, H. (2006). Functions of melanin-concentrating hormone in fish. J. Exp. Zool.305A, 751-760.

77. Song Y, Cone RD. Creation of a genetic model of obesity in a teleost. FASEB J. (2007) 21:2042-9.

78. Poordad, F. Fred MD. The Role of Leptin in NAFLD: Contender or Pretender? Journal of Clinical Gastroenterology: November/December 2004, Volume 38 - Issue 10 - pp 841-843

79. Ekstedt M., Franzén L.E., Mathiesen U.L., et al., Long-term follow-up of patients with NAFLD and elevated liver enzymes, Hepatology, vol. 44, no. 4, pp. 865-873, 2006.

80. Michel, M., Page-McCaw, P. S., Chen, W., and Cone, R. D. (2016). Leptin signaling regulates glucose homeostasis, but not adipostasis, in the zebrafish. Proc. Natl.Acad. Sci. U.S.A. 113, $3084-3089$

81. Flynn, E. J., III, Trent, C. M. and Rawls, J. F. (2009). Ontogeny and nutritional control of adipogenesis in zebrafish (Danio rerio). J. Lipid Res. 50, 1641-1652.

82. Ahima, R. S., and Lazar, M. A. (2013). Physiology. The health risk of obesity better metrics imperative. Science 341, 856-858

83. Song, Y., and Cone, R. D. (2007). Creation of a genetic model of obesity in a teleost. FASEB J. 21, $2042-2049$.

84. Marza, E., Barthe, C., André, M., Villeneuve, L., Hélou, C., and Babin, P. J.(2005). Developmental expression and nutritional regulation of a zebrafish gene homologous to mammalian microsomal triglyceride transfer protein large subunit. Dev. Dyn. 232 , 506-518.

85. Schlegel, A., and Stainier, D. Y. (2006). Microsomal triglyceride transfer protein is required for yolk lipid utilization and absorption of dietary lipids in zebrafish larvae. Biochemistry 45, 15179-15187

86. Greenspan, P., Mayer, E. P., and Fowler, S. D. (1985). Nile red: a selective fluorescent stain for intracellular lipid droplets. J. Cell Biol. 100, 965-973.

87. Jones, K. S., Alimov, A. P., Rilo, H. L., Jandacek, R. J., Woollett, L. A.,and Penberthy, W. T. (2008). A high throughput live transparent animal bioassay to identify non-toxic small molecules or genes that regulate vertebrate fat metabolism for obesity drug development. Nutr. Metab. 5:23.

88. Hölttä-Vuori, M., Salo, V. T., Nyberg, L., Brackmann, C., Enejder, A., Panula, P.,et al. (2010). Zebrafish: gaining popularity in lipid research. Biochem. J. 429,235-242.

89. Anderson, J. L., Carten, J. D., and Farber, S. A. (2011). Zebrafish lipid metabolism: from mediating early patterning to the metabolism of dietary fat and cholesterol. Methods Cell Biol. 101, 111-141.

90. Hasumura, T., Shimada, Y., Kuroyanagi, J., Nishimura, Y., Meguro, S., Takema, Y.,et al. (2012). Green tea extract suppresses adiposity and affects the expression of lipid metabolism genes in diet-induced obese zebrafish. Nutr. Metab. 9:73.

91. Landgraf, K., Schuster, S., Meusel, A., Garten, A., Riemer, T., Schleinitz,D., et al. (2017). Short-term overfeeding of zebrafish with normal orhigh-fat diet as a model for the development of metabolically healthy versus unhealthy obesity. BMC. Physiol.17.4.

92. Zang L, Maddison LA, Chen W. Zebrafish as a model for obesity and diabetes. Front Cell Dev Biol. (2018) 6:91.

93. Imrie, D. and Sadler, K.C. (2010). White adipose tissue development in zebrafish is regulated by both developmental time and fish size. Dev. Dyn. 239, 3013-3023.

94. Schlegel, A., and Stainier, D. Y. (2006). Microsomal triglyceride transfer protein is required for yolk lipid utilization and absorption of dietary lipids in zebrafish larvae. Biochemistry 45, 15179-15187.

95. Tingaud-Sequeira, A., Ouadah, N., and Babin, P. J. (2011 ). Zebrafish obesogenic test: a tool for screening molecules that target adiposity. J. Lipid Res. 52,1765-1772.

96. Miyares RL, de Rezende VB, Farber SA. Zebrafish yolk lipid processing: a tractable tool for the study of vertebrate lipid transport and metabolism. Dis Model Mech. 2014;7:915-927.

97. Minchin JE, Rawls JF. In vivo analysis of white adipose tissue in zebrafish. Methods Cell Biol. 2011;105:63-86.

98. Després JP. The insulin resistance-dyslipidemic syndrome of visceral obesity: effect on patients risk. Obes Res. 1998;6:8S-17S.

99. Fox KR, Hillsdon M. Physical activity and obesity. Obes Rev.2007;8:115-121.

100. Gordon DA, Jamil H. Progress towards understanding the role of microsomal triglyceride transfer protein in apolipoprotein-B lipoprotein assembly. Biochim Biophys Acta. 2000;1486:72-83.

101. Hussain MM, Shi J, Dreizen P. Microsomal triglyceride transfer protein and its role in apoB-lipoprotein assembly. J Lipid Res. 2003;44:22-32. 


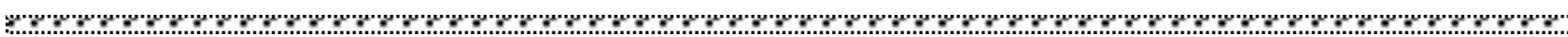
102. Kahn, S.E. The relative contributions of insulin resistance and beta-cell dysfunction to the pathophysiology of Type 2 diabetes. Diabetologia 2003, 46, 3-19.

103. Matsuda, H., \& Shi, Y. B. (2010). An essential and evolutionarily conserved role of protein arginine methyltransferase 1 for adult intestinal stem cells during postembryonic development. Stem Cells, 28, $2073-2083$.

104. Shi, Y. B. (1999). Amphibian metamorphosis: From morphology to molecular biology. New York, NY: John Wiley \& Sons Inc.

105. McMenamin, S. K., Bain, E. J., McCann, A. E., Patterson, L. B., Eom, D. S., Waller, Z. P., Parichy, D. M. (2014). Thyroid hormone-dependent adult pigment cell lineage and pattern in zebrafish. Science, 345, 1358-1361.

106. Matsuda, H., Mullapudi, S. T., Zhang, Y., Hesselson, D., \& Stainier, D. Y. R. (2017). Thyroid hormone coordinates pancreatic islet function during the zebrafish larval to juvenile transition to maintain glucose homeostasis. Diabetes, 66, 2623-2635.

107. Youson, J. H., \& Al-Mahrouki, A. A. (1999). Ontogenetic and phylogenetic development of the endocrine pancreas (islet organ) in fish. General and Comparative Endocrinology, 116, 303-335.

108. Filed, H. A., Dong, P. D., Beis, D., \& Stainier, D. Y. (2003). Formation of the digestive system in zebrafish. II. Pancreas morphogenesis. Developmental Biology, 261, 197-208.

109. Argenton, F., Zecchin, E., \& Bortolussi, M. (1999). Early appearance of pancreatic hormone-expressing cells in the zebrafish embryo. Mechanisms of Development, 87, 217-221.

110. Biemar, F., Argenton, F., Schmidtke, R., Epperlein, S., Peers, B., \& Driever, W. (2001). Pancreas development in zebrafish: Early dispersed appearance of endocrine hormone expressing cells and their convergence to form the definitive islet. Developmental Biology, 230, 189-203.

111. Maddison, L. A., \& Chen, W. (2017). Modeling pancreatic endocrine cell adaptation and diabetes in the zebrafish. Frontiers in Endocrinology, 8, 1-6.

112. Emfinger, C. H., Welscher, A., Yan, Z., Wang, Y., Conway, H., Moss, J. B., Nichols, C. G. (2017). Expression and function of ATP-dependent potassium channels in zebrafish islet $\beta$-cells. Royal Society Open Science, 4, 160808.

113. Singh, S. P., Janjuha, S., Hartmann, T., Kayisoglu, O., Konantz, J., Birke, S., Ninov, N. (2017). Different developmental histories of beta-cells generate functional and proliferative heterogeneity during islet growth. Nature Communications, 8, 664 .

114.Wang, Z.; Xie, Z.; Lu, Q.; Chang, C.; Zhou, Z. Beyond Genetics: What Causes Type 1 Diabetes. Clin. Rev. Allergy Immunol.2017,52, 273-286.

115. Hollander, P.A.; Kushner, P. Type 2 Diabetes Comorbidities and Treatment Challenges Rationale for DPP-4 Inhibitors. Postgrad.Med. 2010, 122, 71-80

116. DeFronzo, R.A.; Ferrannini, E.; Groop, L.; Henry, R.R.; Herman, W.H.; Holst, J.J.; Hu, F.B.; Kahn, C.R.; Raz, I.; Shulman, G.I.; et al.Type 2 diabetes mellitus. Nat. Rev. Dis. Primers 2015, 1, 15019.

117. Defronzo, R.A. Banting Lecture. From the triumvirate to the ominous octet: A new paradigm for the treatment of type 2 diabetes mellitus. Diabetes 2009, 58, 773-795.

118. Khneizer, G.; Rizvi, S.; Gawrieh, S. Non-alcoholic Fatty Liver Disease and Diabetes Mellitus. In Advances in Experimental Medicine and Biology; Springer: New York, NY, USA, 2020; pp. 1-24.

119. A. Kumar, A. Singh, Ekavali, A review on Alzheimer's disease pathophysiology and its management: an update. Pharmacological Reports: PR 67 (2) (2015) 195-203.

120. A. Alexander, S. Saraf, Nose-to-brain drug delivery approach: a key to easily accessing the brain for the treatment of Alzheimer's disease, Neural Regeneration Research 13 (12) (2018) 2102.

121. G.S. Watson, S. Craft, Modulation of memory by insulin and glucose: neuropsychological observations in Alzheimer's disease, Eur J Pharmacol 490 (1-3) (2004) 97-113.

122. K.F. Neumann, L. Rojo, L.P. Navarrete, G. Farias, P. Reyes, R.B. Maccioni, Insulin resistance and Alzheimer's disease: molecular links \& clinical implications, Current Alzheimer Research 5 (5) (2008) 438-447.

123. S.M. de la Monte, Intranasal insulin therapy for cognitive impairment and neurodegeneration: current state of the art, Expert Opinion on Drug Delivery 10 (12) (2013) 1699-1709.

124. Nam, Y.H.; Hong, B.N.; Rodriguez, I.; Ji, M.G.; Kim, K.; Kim, U.J.; Kang, T.H. Synergistic Potentials of Coffee on Injured PancreaticIslets and Insulin Action via KATP Channel Blocking in Zebrafish. J. Agric. Food Chem. 2015, 63, 5612-5621.

125. Kulkarni, A.A.; Conteh, A.M.; Sorrell, C.A.; Mirmira, A.; Tersey, S.A.; Mirmira, R.G.; Linnemann, A.K.; Anderson, R.M. An InVivo Zebrafish Model for Interrogating ROS-Mediated Pancreatic beta-Cell Injury, Response, and Prevention. Oxid. Med. Cell.Longev. 2018, 2018, 1324739.

126.Tseng, Y.C.; Chen, R.D.; Lee, J.R.; Liu, S.T.; Lee, S.J.; Hwang, P.P. Specific expression and regulation of glucose transporters in zebrafish ionocytes. Am. J. Physiol. Regul. Integr. Comp. Physiol. 2009, 297, R275-R290.

127. Jimenez-Amilburu, V.; Jong-Raadsen, S.; Bakkers, J.; Spaink, H.P.; Marin-Juez, R. GLUT12 deficiency during early developmentresults in heart failure and a diabetic phenotype in zebrafish. J. Endocrinol. 2015, $224,1-15$.

128. Blaslov, K.; Naranda, F.S.; Kruljac, I.; Renar, I.P. Treatment approach to type 2 diabetes: Past, present and future. World J. Diabetes 2018, 9, 209-219.

129. Lee, J.; Jung, D.W.; Kim, W.H.; Um, J.I.; Yim, S.H.; Oh, W.K.; Williams, D.R. Development of a highly visual, simple, and rapid testfor the discovery of novel insulin mimetics in living vertebrates. ACS Chem. Biol. 2013, 8, 18031814. 


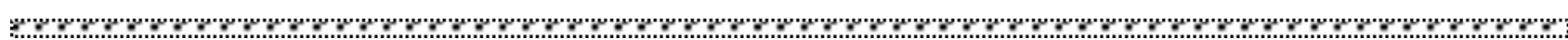
130. Elo, B.; Villano, C.M.; Govorko, D.; White, L.A. Larval zebrafish as a model for glucose metabolism: Expression of phospho-enolpyruvate carboxykinase as a marker for exposure to anti-diabetic compounds. J. Mol. Endocrinol.2007, 38, 433-440.

131. Jurczyk, A.; Roy, N.; Bajwa, R.; Gut, P.; Lipson, K.; Yang, C.; Covassin, L.; Racki, W.J.; Rossini, A.A.; Phillips, N.; et al. Dynamic glucoregulation and mammalian-like responses to metabolic and developmental disruption in zebrafish. Gen. Comp. Endocrinol.2011, 170, 334-345.

132. Okamoto, H.; Cavino, K.; Na, E.; Krumm, E.; Kim, S.Y.; Cheng, X.; Murphy, A.J.; Yancopoulos, G.D.; Gromada, J. Glucagonreceptor inhibition normalizes blood glucose in severe insulin-resistant mice. Proc. Natl. Acad. Sci. USA 2017, 114, 2753-2758.

133. Lee, Y.H.; Wang, M.Y.; Yu, X.X.; Unger, R.H. Glucagon is the key factor in the development of diabetes. Diabetologia 2016, 59,1372-1375.

134. Gut, P.; Baeza-Raja, B.; Andersson, O.; Hasenkamp, L.; Hsiao, J.; Hesselson, D.; Akassoglou, K.; Verdin, E.; Hirschey, M.D.;Stainier, D.Y. Whole-organism screening for gluconeogenesis identifies activators of fasting metabolism. Nat. Chem. Biol.2013, 9,97-104.

135. Gutierrez, R.M.P.; Flores, J.M.M.; Gonzalez, A.M.N. Anti-inflammatory effect of procumbenoside B from Justicia spicigera onlipopolysaccharide-stimulated RAW 264.7 macrophages and zebrafish model. Pharmacogn. Res. 2018, 10, 218-224.

136. Kim, E.-A.; Kang, M.-C.; Lee, J.-H.; Kang, N.; Lee, W.; Oh, J.-Y.; Yang, H.-W.; Lee, J.-S.; Jeon, Y.-J. Protective effect of marine brown algal polyphenols against oxidative stressed zebrafish with high glucose. RSC Adv. 2015, 5, 25738-25746.

137. Statescu C, Honceriu C, Trus C, Does Magnesium Deficient Diet and its Associated Metabolic Dysfunctions Induces Anxiety-like Symptoms Further cardiovascular relevance. Revista de Chimie , 2019; 70: 3579-3581.

138. Kinda P, Guenné S, Basile T, Ouédraogo N, Compaoré M, Bayala B, Bild W, Dobrin R, et al. Brain protection and anti-amnesic effects assessment of Datura Innoxia Mill. aqueous extracts. Farmacia 2020, 68; 2: 261-268.

139. Massaoudi Y, Ciobica A, Dobrin I, Hassouni M. Halophilic bacteria - a potential therapeutical approach for autism? Romanian Biotechnological Letters 2019; 24, 826-836.

140. Prepelita R. Cristofor AC, Dobrin R, Trus C, Ciobica A, Chirita R. The Serotonin-Dopamine Relationship on the Aggression-Suicidal Risk Axis in Patients with Major Depression Disorder: Describing Some Social Implications. Revista de Cercetare si Interventie Sociala 2019; 65: 111-130.

141. Dobrin I. Chirita R. Dobrin R. Birsan M. Stefanescu C. Trus C. Cristofor A.C. Social Intervention as an Adjuvant Therapy for Patients with Schizophrenia. Revista de Cercetare si Interventie Sociala 2020; 68: 261-270.

142. Luca M, Di Mauro M, Perry G. Neuropsychiatric Disturbances and Diabetes Mellitus: The Role of Oxidative Stress. Oxid Med Cell Longev 2019 Jul 4;2019:5698132.

143. Foley DL, Mackinnon A, Morgan VA, Castle DJ, Waterreus A, Galletly CA. Comorbid Diabetes and Depression in a National Sample of Adults With Psychosis. Schizophr Bull 2018 Jan 13;44(1):84-92.

144. Martins LB, Monteze NM, Calarge C, Ferreira AVM, Teixeira AL. Pathways linking obesity to neuropsychiatric disorders. Nutrition 2019 Oct;66:16-21.

145. Ogrodnik M, Zhu Y, Langhi LGP, Tchkonia T, Krüger P, Fielder E, Victorelli S, Ruswhandi RA, Giorgadze N, Pirtskhalava T, Podgorni O, Enikolopov G, Johnson KO, Xu M, Inman C, Palmer AK, Schafer M, Weigl M, Ikeno Y, Burns TC, Passos JF, von Zglinicki T, Kirkland JL, Jurk D. Obesity-Induced Cellular Senescence Drives Anxiety and Impairs Neurogenesis. Cell Metab 2019 May 7;29(5):1061-1077.e8.

146. Seabrook LT, Borgland SL. The orbitofrontal cortex, food intake and obesity. J Psychiatry Neurosci 2020 Sep 1;45(5):304-312.

147. Kinkel, M. D., and Prince, V. E. (2009). On the diabetic menu: zebrafish a sa model for pancreas development and function. Bioessays 31, 139-152.

148. Tiso, N., Moro, E., and Argenton, F. (2009). Zebrafish pancreas development. Mol.Cell. Endocrinol. 312, 24-30.

149. Eames, S. C., Philipson, L. H., Prince, V. E., and Kinkel, M. D. (2010). Blood sugarmeasurement in zebrafish reve als dynamics of glucose homeostasis. Zebrafish 7, 205-213.

150. Eames Nalle, S. C., Franse, K. F., and Kinkel, M. D. (2017). Analysis of pancreatic disease in zebrafish. Method Cell Biol. 138, 271-295.

151. Jurczyk, A., Roy, N., Bajwa, R., Gut, P., Lipson, K., Yang, C., et al. (2011). Dynamic glucoregulation and mammalian-like responses to metabolic and developmental disruption in zebrafish. Gen. Comp. Endocrinol. 170, 334345 .

152. Jagadeeswaran, P., Sheehan, J. P., Craig, F. E., and Troyer, D. (1999). Identification and characterization of zebrafish thrombocytes. Br. J. Haematol. 107, 731- 738.

153. Velasco-Santamaría, Y. M., Korsgaard, B., Madsen, S. S., and Bjerregaard, P.(2011). Bezafibrate, a lipid-lowering pharmaceutical, as a potential endocrine disruptor in male zebrafish (Danio rerio). Aquat. Toxicol. 105, $107-118$.

154. Zang, L., Shimada, Y., and Nishimura, N. (2017). Development of a novel zebrafish model for type 2 diabetes mellitus. Sci. Rep. 7:1461.

155. Capiotti, K. M., Antonioli, R. Jr., Kist, L. W., Bogo, M. R., Bonan, C. D., and Da Silva, R. S. (2014). Persistent impaired glucose metabolism in a zebrafish hyperglycemia model. Comp. Biochem. Physiol. B Biochem. Mol. Biol. $171,58-65$. 
Bulletin of Integrative Psychiatry $\bigcirc$ New Series OSeptember 2021 Year XXVII ONo. 3(90)/31

20. 156. Maddison, L. A., Joest, K. E., Kammeyer, R. M., and Chen, W. (2015). Skeletal muscle insulin resistance in zebrafish induces alterations in be ta-cell numberand glucose tolerance in an age- and diet-dependent manner. Am. J. Physiol. Endocrinol. Metab. 308, E662-E669.

157. V.Connaughton, C. Baker, L.Fande et al., Altrnate Immersion in an External Glucose Solution Differentially Affects Blood Sugar Values in Older Versus Younger Zebrafish Adults. Zebrafish. 2016;13

\section{Correspondence}

Irina Dobrin,

MD, PhD, lecturer, psychiatrist, "Grigore T. Popa" University of Medicine and Pharmacy, 16, Universitatii Street, 700115, Iasi, Romania, irinadobrin2002@gmail.com

Submission: 15 jul 2021

Acceptance: 28 aug 2021 